\title{
Endoscopic radial artery harvesting for coronary artery bypass grafting. A single center evolving experience
}

\author{
Martin Simek, Pavel Marcian, Marek Gwozdziewicz, Fluger Ivo, Patrick Tobbia, Vladimir Lonsky
}

\begin{abstract}
Aim. We sought to evaluate our experience with endoscopic radial artery harvesting for coronary artery bypass grafting (CABG).

Methods. From October 2005 to June 2010, 50 patients who underwent endoscopic radial artery harvesting for an elective CABG were prospectively assessed for harvesting characteristics, complications, postoperative and mid-term outcomes.

Results. There were 34 (68\%) males and 16 (32\%) females, average age 60.8 \pm 9.2 years. All but two RA grafts (96\%) were successfully harvested endoscopically. Mean harvesting time was $46.2 \pm 9.3 \mathrm{~min}$ and mean length of harvested grafts was $23.4 \pm 2.2 \mathrm{~cm}$. In the post-operative period there were no wound-healing complications; residual forearm edema was recorded in 6 patients (12\%) and peripheral neuropathy in 4 patients (8\%). At 3 months after the surgery, peripheral neuropathy and residual edema persisted in 2 patients (4\%). A significant drop of overall harvesting time $(56.2 \pm 18.6$ vs. $38.6 \pm 8.6 \mathrm{~min}, P<0.05)$ and forearm ischemia time $(41.8 \pm 12.7$ vs. $24.2 \pm 3.2 \mathrm{~min}, P<0.01)$ was found between first and last ten cases in the group.
\end{abstract}

Conclusion. Endoscopic radial artery harvesting was associated with low risk of post-harvesting complications and most of these disappeared within a 3 months follow-up. However, there was a significant learning curve.

Key words: radial artery, endoscopic harvesting, coronary artery bypass grafting

Received: August 10, 2011; Accepted with revision: February 27, 2012; Available online: May 10, 2012

http://dx.doi.org/10.5507/bp.2012.032

Department of Cardiac Surgery, University Hospital Olomouc and Faculty of Medicine and Dentistry, Palacky University Olomouc, Czech Republic

Corresponding author:Martin Simek, e-mail:martin.simek@c-mail.cz

\section{INTRODUCTION}

Radial artery (RA) has been widely adopted for coronary artery bypass grafting since the mid-1990s when interest in this practise was renewed ${ }^{1}$. Open RA harvesting (ORAH) is considered to be safe and well-accepted for its simplicity and minimal trauma to the graft ${ }^{2}$. However, uninterrupted incision occupying almost the whole length of the volar forearm is associated with some risk of complications, dissatisfaction with the cosmetic result or hypertrophic scar formation, particularly in younger patients and women ${ }^{3}$. In an effort to minimize surgical trauma, endoscopic radial artery harvesting (ERAH) has evolved. Although some reports suggest reduction of post-harvesting complications and excellent cosmetic results, this technique has not been yet accepted as widely as endoscopic vein harvesting worldwide ${ }^{4}$. We sought to evaluate our experience with ERAH and to analyze the effects of evolving experience on the results.

\section{PATIENTS AND METHODS}

From October 2005 to June 2010, 50 patients undergoing elective coronary artery bypass grafting underwent ERAH at our institution. The RAs were harvested preferably from the non-dominant arm, simultaneously with sternotomy and left internal mammary artery harvesting. Its use for grafting was based on the surgeon's choice.

\section{Preoperative evaluation of RA}

The adequacy of collateral blood flow was assessed preoperatively by modified Allen test and duplex ultrasound study. Exclusion criteria included: emergency surgery, positive Allen test (refilling time over $5 \mathrm{~s}$ ), previous upper extremity trauma, Raynaud's disease or vasculitis. Further, based on duplex ultrasound study $(10 \mathrm{MHz}$ probe, SONOS $5500^{\mathrm{TM}}$, Agilent Technologies Inc., Andover, USA), patients with significant stenosis ( $>50 \%)$ of brachial, ulnar or radial artery, calcification in RA wall, intimo-medial thickening over $0,6 \mathrm{~mm}$, and diameter of RA below $2 \mathrm{~mm}$ were excluded from RA harvesting.

\section{Harvesting technique}

At the time of surgery, a tourniquet was placed on the upper arm prior to draping the patient. Then the forearm was supinated on the arm board positioned at $80^{\circ}$ degrees from the table. A $3-\mathrm{cm}$ longitudinal incision was made roughly $1 \mathrm{~cm}$ proximally from radial styloid just above the palpable RA. The distal segment of RA with concomitant veins was freed from surrounding tissue, and the fascia was cut with scissors as proximally as possible under direct vision to create space for insertion of the dissecting cannula tip. Once the distal segment of the RA was 
exposed, the forearm was elevated and wrapped tightly with a compressive bandage. The tourniquet was inflated $30 \mathrm{mmHg}$ above the systolic artery pressure, wrapping released and the forearm replaced on the table. ERAH was carried out using Vasoview $6^{\mathrm{TM}}$ (47 procurements) and Hemopro ${ }^{\mathrm{TM}}$ (3 procurements) vessel harvesting system (Maquet GmbH, Germany). The system consists of a $7 \mathrm{~mm}$ 0-degree extended endoscope and one disposal harvesting cannula. The whole procedure was facilitated with $\mathrm{CO}_{2}$ insufflation, however the insufflation pressure was limited to $5 \mathrm{mmHg}$. The RA in continuity with satellite veins was gently dissected with the aid of a conical dissection cannula attached directly to the endoscope. The location of the endpoint of the dissection was based on visualisation of the recurrent branch of the RA or the venous plexus located just proximal in the antecubital fossa. Afterwards, the harvesting cannula was put on the endoscope, and either bipolar scissor (Vasoview $6^{\mathrm{TM}}$ ) or direct current-powered sealing jaw (Hemopro ${ }^{\mathrm{TM}}$ ) was use for the fasciotomy of RA's tributaries division. Once the graft was completely freed, both ends were grasped with a mosquito clamp and dissected, in the proximal part with the aid of a $3 \mathrm{~mm}$ stab incision, in the distal, throughout the initial entry incision. Skin incisions were closed with 4-0 absorbable subcuticular suture (Vicryle Plus ${ }^{\mathrm{TM}}$, Ethicon, Scotland) and after Redon's drain insertion, a bandage was placed on the forearm. A small dose of heparin, $2500 \mathrm{UI}$ intravenously, has been was given prior to the initial RA dissection since 2009.

\section{Graft preparing}

All harvested RAs were prepared in the same manner, including closing side branches with metallic clips, atraumatically flushing artery with tepid heparinized saline solution and storing in bath with calcium channel blocker verapamil (Lekoptin, Lek Pharmaceuticals, Slovenia). To avoid RA spasm, intravenous administration of nitrate (NitroPohl, Pohl-Boskamp GmbH, Germany) was begun immediately after grafting if hemodynamic conditions allowed it. After the procedure, selective calcium channel blocker amlodipine (Zorem, Teva Czech Industries, Czech Republic) was administrated in a dose of up to $10 \mathrm{mg}$ daily.

\section{Follow-up}

All data were collected prospectively, including demographic, operative, procedural characteristics (harvesting time, length of graft) and procedural complications (conversion rate, bleeding, blood loss and graft injury rate). Post-harvesting surgical complications including hematomas, residual forearm edema, pain, and woundhealing disturbances, hand ischemia, and neurological disturbances including sensory (numbness or parenthesis) or motor impairment (hand grip test) was followed up to the $5^{\text {th }}$ postoperative day, and at 3 months after the surgery.

\section{Statistics}

Data were analyzed with SPSS 10.0 statistical analysis software (SPSS Inc. Chicago, USA). They were presented
Table 1. Patient characteristics $(n=50)$.

\begin{tabular}{lcc}
\hline & $\mathrm{n}$ & $\%$ \\
\hline Age (years) & $60.8 \pm 9.2$ & \\
Male/female ratio & $34 / 16$ & $68 / 32$ \\
BMI & $28.4 \pm 4.4$ & \\
Diabetes & 13 & 26 \\
PVD & 8 & 16 \\
Immunosuppression & 3 & 6 \\
LVEF (\%) & $45.9 \pm 6.2$ & \\
\hline
\end{tabular}

BMI - body mass index

PVD - peripheral vascular disease

LVEF - left ventricle ejection fraction

Table 2. Operative characteristics $(n=50)$.

\begin{tabular}{lcc}
\hline & $\mathrm{n}$ & $\%$ \\
\hline CABG (on-pump/off-pump) & $27 / 19$ & $58 / 42$ \\
CABG plus other procedure & 2 & 4 \\
Re-do CABG & 2 & 4 \\
Operative time (min) & $219.5 \pm 56.6$ & \\
CPB time (min) & $66.8 \pm 19.7$ & \\
Cross clamp time (min) & $46.7 \pm 19.8$ \\
No. of peripheral anastomoses & $3.1 \pm 0.76$ & \\
No. of peripheral anastomoses on & $1.52 \pm 0.62$ & \\
RA &
\end{tabular}

Distal anastomosis of RA

$\begin{array}{lcc}\text { to LAD } & 1 & 2 \\ \text { to diagonal } & 17 & 34 \\ \text { to circumflex } & 34 & 68 \\ \text { to RCA } & 23 & 46\end{array}$

Proximal anastomosis of RA

\begin{tabular}{lcc} 
to ascending aorta & 22 & 44 \\
to LITA & 20 & 40 \\
to RITA & 8 & 16 \\
\hline
\end{tabular}

CABG - coronary artery bypass grafting

CPB - cardiopulmonary bypass

LAD - left anterior descending

RCA - right coronary artery

LITA - left internal thoracic artery

RITA - right internal thoracic artery

as means with standard deviation. Categorical data was compared by $\chi^{2}$ test and Fisher exact test. Student's t test was used to compare normative data. Probability less than 0.05 was considered statistically significant. 

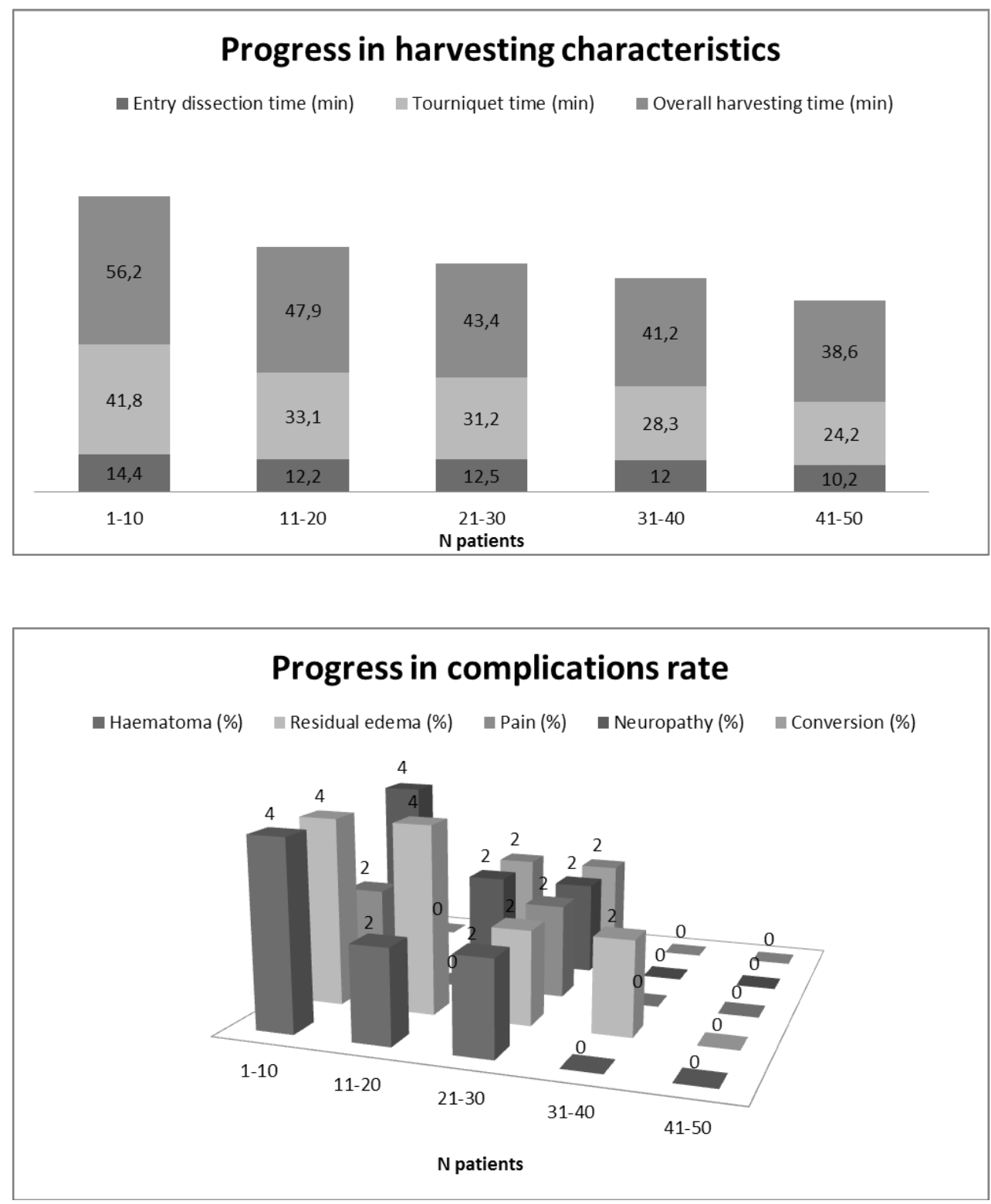

Fig. 1. Progress in harvesting characteristics.

Fig. 2. Progress in complications rate.

\section{RESULTS}

There were 34 (68\%) males and 16 (32\%) females, average age $60.8 \pm 9.2$ years. The majority underwent only CABG (96\%), more often with the aid of cardiopulmonary bypass (62\%). Mean number of peripheral anastomoses was $3.1 \pm 0.76$, on RA grafts $1.52 \pm 0.62$. RA grafts were targeted to LAD, diagonal, circumflex, RCA territory in 1 (2\%), 17 (34\%), 34 (68\%), 23 (46\%) of cases, respectively. As inflow for RA grafts, the ascending aorta was used in $22(44 \%)$, left internal thoracic artery in $20(40 \%)$, and right internal mammary artery in $8(16 \%)$ of cases. Detailed demographic and operative characteristics are summarized in Table 1, 2.

All but two RA grafts (96\%) were successfully harvested endoscopically. One case was converted due to venostatic bleeding from injured satellite vein when the arm was inaccurately compressed during tourniquet inflation, and the second owing to hemodynamic collapse caused by right ventricle injury during re-do sternotomy. One patient needed to be revised through extended counter incision for overwhelming bleeding due to ligature slide from proximal RA stump just after finishing the procedure. Mean harvesting time was $46.2 \pm 9.3$ min including $34.5 \pm 8.9 \mathrm{~min}$ of forearm ischemia, and mean length of harvested grafts was $23.4 \pm 2.2 \mathrm{~cm}$. None of grafts was macroscopically injured or excluded from grafting. Total incisional length counting both entry and counter incision was $3.7 \pm 0.8 \mathrm{~cm}$. Blood loss measured from drainage discharge was $23.4 \pm 19.6 \mathrm{~mL}$. Full harvesting characteristics are displayed in Table 3. Although all procedures were performed by one surgeon (M.S.) well-experienced with endoscopic vein harvesting, a significant learning curve was found. Comparing each harvesting characteristic, significant drop in overall harvesting time (56.2 \pm 18.6 vs. $38.6 \pm 8.6 \mathrm{~min}, P<0.05$ ), forearm ischemia time ( $41.8 \pm 12.7$ vs. $24.2 \pm 3.2 \mathrm{~min}, P<0.05$ ), and entry incision RA release - dissection time ( $14.4 \pm 8.2$ vs. $10.2 \pm 3.4 \mathrm{~min}$, $P<0.05$ ) was found between first and last ten cases in the group (Fig. 1). Likewise, increasing experience was re- 
Table 3. Harvesting characteristics $(n=50)$.

\begin{tabular}{lcc}
\hline & $\mathrm{n}$ & $\%$ \\
\hline Non-dominant hand & 47 & 94 \\
Harvested from the left hand & 46 & 92 \\
Tourniquet usage & 46 & 92 \\
Length of harvested RA (cm) & $23.4 \pm 2.2$ & \\
Overall harvesting time (min) & $46.2 \pm 9.3$ & \\
Forearm ischemia time (min) & $34.5 \pm 8.9$ & \\
& & \\
No. of skin incisions & $2 \pm 0$ & \\
Overall length of skin incisions & $3.7 \pm 0.8$ \\
(cm) & 1 & 2 \\
Revision for bleeding & 2 & 0 \\
Conversion to the open harvest & 0 & \\
No. of graft injury & $23.4 \pm 19.6$ & \\
Blood loss (ml) &
\end{tabular}

Table 4. Post-harvesting complications ( $n=50)$.

\begin{tabular}{lcccc}
\hline & \multicolumn{2}{c}{5 th POD } & \multicolumn{2}{c}{3 months } \\
\cline { 2 - 5 } Hematoma & $\mathrm{n}$ & $\%$ & $\mathrm{n}$ & $\%$ \\
Local & 10 & 20 & 0 & \\
Diffuse & 4 & 8 & 0 & \\
Dehiscence & 0 & & 0 & \\
Necrosis & 0 & & 0 & \\
Wound infec- & 0 & & 0 & \\
tion & & & & \\
Residual & 6 & 12 & 2 & 4 \\
edema & 2 & 4 & 0 & 0 \\
Pain & 4 & 8 & 2 & 4 \\
Neuropathy & 3 & 6 & 2 & 4 \\
SBRN & 0 & 0 & 0 & 0 \\
LCAN & 1 & 2 & 0 & 0 \\
MN & & & & \\
\hline
\end{tabular}

POD - postoperative day

SBRN - superficial branch of radial nerve

LACN - lateral antebrachial cutaneous nerve

MN - median nerve flected in decreased complications and conversion rate over time (Fig. 2).

On the post-operative period ( $5^{\text {th }}$ post-operative day) there were no wound-healing complications including dehiscence, necrosis or incision infection. Residual arm edema occurred in 6 patients (10\%) and was associated with diffuse hematoma formation within the harvesting tunnel in 5 patients (10\%). Peripheral neuropathy was experienced in 4 patients (8\%), 3 of them complained of dorsal thenar numbness, and one of paresthesias of the $2^{\text {nd }}$ and $3^{\text {rd }}$ volar fingers showing impairment of the superficial branch of the radial nerve (SBRN), and sensory part of median nerve (MN), respectively. Two patients (4\%) complained of mild arm pain not requiring pain medication. At 3 months after the surgery, peripheral neuropathy persisted in two patients (4\%), both complained of unbounded small area of dorsal thenar numbness, and residual arm edema was also found in two patients (4\%). No ischemic complications, inability to perform tasks, or return to previous work because of hand impairment. The post-harvesting complication rate is summarized in Table 4.

During the 3 months follow-up, one patient died (2\%) of a sequela of cerebrovascular accident on 18 th postoperative day. A total of 10 patients (20\%) underwent angiography to confirm the patency of the grafts in the early post-operative period, 2 of them (4\%) because of post-operative myocardial ischemia, and 8 (16\%) for others reasons connected to off-pump complete arterial revascularization using composite graft of right internal thoracic and RA. In the first group, one stenosis in distal anastomosis on the obtuse marginal branch was displayed and solved by intracoronary bare metal stent placement. In the second group, all RA and distal anastomoses were well-patent. However, a stenosis in the anastomosis of the composite right internal thoracic to RA graft was revealed.

\section{DISCUSSION}

Improvement in harvesting techniques together with broadly-accepted anti-spasm medical therapy has led to renewed interest in the radial artery as an arterial conduit over time ${ }^{1}$. The arterial wall structure, comparable diameter, low-risk of harvesting site complications, and longterm preserved flow-mediated vasodilatation are perceived advantages of RA over the great saphenous vein (GSV) (ref. ${ }^{5,6}$ ). Although, a number of observational studies have demonstrated the superiority of RA in terms of better patency and clinical outcome, randomized trials suggested only better angiographic results of RA in 1-year and 5-year follow-up with no difference in clinical outcome e $^{5-11}$. Moreover, dealing with less tight coronary lesions $(<80 \%)$, particularly in the right coronary artery territory, and with the group of patients 70+, use of RA did not carry any benefit of importance over GSV (ref. ${ }^{10,11}$ ).

RA harvesting performed through an uninterrupted incision in Reyes's modification is simple, quick, and safe 
towards radial artery ${ }^{12}$. The risk of severe post-harvesting complications leading to hand disability as a consequence of hand ischemia or major neuronal trauma is extremely rare if the surgical technique and pre-operative hand collateral blood flow evaluation are carried out properly ${ }^{2,7,12}$. However, neuropathic sensory disturbances in the terminal area of the superficial branch of the radial nerve (SBRN), lateral antebrachial cutaneous nerve (LACN), and sensory part of median nerve (MN) are clinically detectable in $12-51 \%$ of cases in the postoperative period and even persist in $8-12 \%$ patients 1 year after the surgery ${ }^{3,13,14}$. In addition, in $3-5 \%$ of patients had some motor deficit which was caused by injury to the median or the motor branch of the radial nerve ${ }^{14}$. According to neurophysiologic study, axonal degeneration lesions of radial and median nerve are detectable almost in $70 \%$ cases $^{15,16}$. Neuronal injury after RA harvesting can be caused by direct surgical trauma accompanied dissection or overuse of electrocautery, or rather owing to indirect trauma as a consequence of tissue edema, hematoma formation or compartmental forces. This aside, there is also a risk of microvascular malperfusion despite the competency of collateral flow ${ }^{3,13}$. Some sensory loss and/or motor weakness following RA harvesting, mostly in the thumb area, can be perceived very sensitively by the patient, particularly when it produces some hand limitation in regular or work activities even when the impairment was assessed as minor or negligible by the physician ${ }^{14}$.

Evolving experience with endoscopic vein harvesting shows significant reduction in harvesting site-related complications. For this reason the radial artery concept was introduced: to reduce the risk of complication risk, particularly neurological, and improve the cosmetic result ${ }^{17,18}$. The initial experience confirmed the feasibility and safety of ERAH which was consequently confirmed on a large patient cohort of 300 cases $^{19}$. Prospective observational study comparing ERAH with ORAH, showed significant decrease in motor and sensory neuronal disturbances assessed postoperatively ( $10 \%$ vs. $1 \%, 31 \%$ vs. $18 \%$ ) (ref. $\left.{ }^{20}\right)$, 1 month ( $8 \%$ vs. $1 \%, 26 \%$ vs $8 \%$ ) $\left(\right.$ ref. $\left.^{20}\right)$, and 3 months after the surgery ( $5 \%$ vs. $0 \%, 14 \%$ vs. $4 \%$ ) (ref. ${ }^{20}$ ), respectively. Further, significantly lower incidence of wound healing complications including massive hematoma $(0 \%$ vs. $5 \%$ ) and wound infection ( $0 \%$ vs. $7 \%$ ) were recorded ${ }^{20}$. Other retrospective observational studies, comparing endoscopic and open technique also showed reduction of wound healing and neurological complications, in favor of ERAH. Moreover, significantly reduced impairment in work and regular daily activities ( $0 \%$ vs. $12 \%$ ) and postoperative pain ( $0 \%$ vs. $8 \%$ ) was observed ${ }^{21}$. Avoidance of long forearm skin incision in ERAH minimizes the risk of the LACN injury in contrast to ORAH. The risk of SBRN is comparable in both techniques due to its anatomical proximity to RA ( ref. $^{22}$ ). Functional and histological assessment of conduits taken endoscopically and conventionally revealed no differences in alteration of vasoreactivity or endothelial integrity between groups in prospective randomized trial ${ }^{23}$. Assessment of one-year graft patency using 64-slice computer tomography showed no differences between ERAH and ORAH groups (78\% vs. $76 \%$ ) $\left(\right.$ ref. $\left.^{24}\right)$. Although, several harvesting systems are employing for ERAH, there are no data comparing the influence on bipolar electrocauthery, harmonic scalpel or direct current on the conduit quality used for branch division in each system. However, the issue of conduit quality harvested endoscopically needs to be appraised carefully in light of the results of optical coherence tomography imaging and sub-analysis of the PREVENTIV study ${ }^{25,26}$.

Our results showed a significant learning curve of ERAH even with ample previous experience using endoscopic vein harvesting techniques. Thus, procedural time remained longer than with ORAH in our setting. Moreover, there was additional call on time for preparing endoscopic equipment, its assemblage, and also attachment of pneumatic tourniquet if used.

The risk of procedural complications appears to be very low. One procedure needed to be converted to a traditional approach due to bleeding from a satellite vein. Another delayed bleeding due to ligature slide was controlled through proximal incision. None of the harvested grafts were injured when assessed macroscopically. Similarly, we did not face any wound-healing problems or limitation of daily hand function. In accordance with previously published data, the neuronal injury rate was low ( $8 \%)$ and declined markedly within follow-up (4\%). The small entry incision in the distal volar forearm hindered of impairment of LCAN well-known in ORAH, however, the injury SBRN was not entirely avoidable in the endoscopic technique.

The quality of harvested grafts is closely dependent on the preoperative quality of RA and handling with graft, particularly within harvesting. Duplex ultrasound is an easy, fast and feasible tool for assessment of morphology and flow in forearm vessels and might be demanding to exclude inappropriate RAs for grafting, particularly in diabetics and peripheral vascular disease patients ${ }^{27}$. The risk of potential graft injury caused by ERAH is debated, against the backdrop of endoscopic vein harvesting $(\mathrm{EVH})$ results. Although, vasoreactivity and patency rate of harvested RA graft seem to be comparable, a higher incidence of intimal tears was displayed on optical coherence tomography imaging ${ }^{25,28}$. Analogously to EVH, from 2009 we have adopted some precautions in ERAH technique including routine low-dose pre-heparization, no port-seal and minimal $\mathrm{CO}_{2}$ insufflation pressure, and use of the hemoseal system with minimal thermal spread. Nonetheless, meticulous harvesting technique is still the keynote.

So far, no study has evaluated the cost-effectiveness of ERAH. In contrast to EVH when significant decrease of wound-healing complications, in-hospital stay, and need for further out patient care support its cost-effectiveness, it remains questionable whether reduction of neurological impairment and better cosmetic results outweigh the cost of ERAH, particularly if single use devices are employed ${ }^{29}$.

We are aware that there was only a total of 91 RAs harvested ( $54.9 \%$ endoscopically) during the tracking period. The low number of ERAH performed for this study 
was partially due to our policy of prioritizing the use of both internal thoracic arteries for LCA territory grafting and reluctance to placing arterial grafts in RCA territory, particularly if the targeted stenosis appeared to be less than $90 \%$. Further, cost and the availability of only 1 surgeon qualified to perform ERAH impacted on the size of the study. Also we are aware that the non-comparative observational design represents the main limitation in our study.

\section{CONCLUSION}

Our experience confirms the feasibility and safety profile of ERAH. The risk of harvesting and post-harvesting complications was low and harvesting characteristics improved with a steep learning curve.

\section{REFERENCES}

1. Acar C, Ramsheyi A, Pagny JY, Jebara V, Barrier P, Fabiani JN, Deloche A, Guermonprez JL, Carpentier A. The radial artery for coronary artery bypass grafting: clinical and angiographic results at five years. J Thorac Cardiovasc Surg 1998;116:981-9.

2. Meharwal ZS, Trehan N. Functional status of the hand after radial artery harvesting: results in 3,977 cases. Ann Thorac Surg 2001;72:1557-61.

3. Denton TA, Trento L, Cohen M, Kass RM, Blanche C, Raissi S, Cheng W, Fontana GP, Trento A. Radial artery harvesting for coronary bypass operations: neurologic complications and their potential mechanisms. J Thorac Cardiovasc Surg 2001;121:951-6.

4. Terada Y, Uchida A, Fukuda I, Hochberg J, Mitsui T, Sato F. Endoscopic harvesting of the radial artery as a coronary artery bypass graft. Ann Thorac Surg 1998;66:2123-4.

5. Buxton BF, Hayward PA, Newcomb AE, Moten S, Seevanayagam S, Gordon I. Choice of conduits for coronary artery bypass grafting: craft or science? Eur J Cardiothorac Surg 2009;35:658-70.

6. Webb CM, Moat NE, Chong CF, Collins P. Vascular reactivity and flow characteristics of radial artery and long saphenous vein coronary bypass grafts: a 5-year follow-up. Circulation 2010;122:861-7

7. Tatoulis J, Buxton BF, Fuller JA. Patencies of 2127 arterial to coronary conduits over 15 years. Ann Thorac Surg 2004;77:93-101.

8. Collins P, Webb CM, Chong CF, Moat NE. Radial artery versus saphenous vein patency randomized trial: five-year angiographic followup. Circulation 2008;117:2859-64.

9. Benedetto U, Angeloni E, Refice S, Sinatra R. Radial artery versus saphenous vein graft patency: meta-analysis of randomized controlled trials. J Thorac Cardiovasc Surg 2010;139:229-31.

10. Buxton BF, Raman JS, Ruengsakulrach P, Gordon I, Rosalion A Bellomo R, Horrigan M, Hare DL. Radial artery patency and clinical outcomes: five-year interim results of a randomized trial. J Thorac Cardiovasc Surg 2003;125:1363-71.

11. Desai ND, Cohen EA, Naylor CD, Fremes SE. A randomized comparison of radial-artery and saphenous-vein coronary bypass grafts. Radial Artery Patency Study Investigators. N Engl J Med 2004;351:2302-9.

12. Reyes AT, Frame R, Brodman RF. Technique for harvesting the radial artery as a coronary artery bypass graft. Ann Thorac Surg 1995;59:118-26.
13. Siminelakis $S$, Karfis E, Anagnostopoulos C, Toumpoulis I, Katsaraki A, Drossos $G$. Harvesting radial artery and neurologic complications. J Card Surg 2004;19:505-10.

14. Saeed I, Anyanwu AC, Yacoub MH, Amrani M. Subjective patient outcomes following coronary artery bypass using the radial artery: results of a cross-sectional survey of harvest site complications and quality of life. Eur J Cardiothorac Surg 2001;20:1142-6

15. Reyes G, Traba A, López L, Pinto A, Duarte J, Vallejo JL. Neurological damage after radial artery harvesting in coronary surgery: a direct measure. Interact Cardiovasc Thorac Surg 2006;5:433-8.

16. Doğan OV, Düzgün C, Ozeren M, Alanoğlu E, Doğan S, Simşek E, Yücel E. Subclinical injury to forearm nerves during radial harvesting: electrophysiologic study. J Card Surg. 2006;21:151-4.

17. Shapira OM, Eskenazi BR, Hunter CT, Anter E, Bao Y, Murphy R, Lazar $\mathrm{HL}$, Shemin RJ. Endoscopic versus conventional radial artery harvest-is smaller better? J Card Surg 2006;21:329-35.

18. Casselman FP, La Meir M, Cammu G, Wellens F, De Geest R, Degrieck I, Van Praet F, Vermeulen Y, Vanermen H. Initial experience with an endoscopic radial artery harvesting technique. J Thorac Cardiovasc Surg 2004; 128:463-6.

19. Connolly MW, Torrillo LD, Stauder MJ, Patel NU, McCabe JC, Loulmet DF, Subramanian VA. Endoscopic radial artery harvesting: results of first 300 patients. Ann Thorac Surg 2002;74:502-5.

20. Patel AN, Henry AC, Hunnicutt C, Cockerham CA, Willey B, Urschel $\mathrm{HC}$. Endoscopic radial artery harvesting is better than the open technique. Ann Thorac Surg 2004;78:149-53.

21. Medalion B, Fuks A, Sharoni E, Stamler A, Snir E, Vidne B, Porat E. Limb performance and patient satisfaction after radial artery harvesting: endoscopic versus open techniques. Surg Endosc 2008;22:2638-42.

22. Bleiziffer S, Hettich I, Eisenhauer B, Ruzicka D, Voss B, Bauernschmitt $R$, Lange R. Neurologic sequelae of the donor arm after endoscopic versus conventional radial artery harvesting. J Thorac Cardiovasc Surg 2008;136:681-7.

23. Shapira OM, Eskenazi BR, Anter E, Joseph L, Christensen TG, Hunter CT, Lazar HL, Vita JA, Shemin RJ, Keaney JF Jr. Endoscopic versus conventional radial artery harvest for coronary artery bypass grafting: functional and histologic assessment of the conduit. J Thorac Cardiovasc Surg 2006;131:388-94.

24. Bleiziffer S, Hettich I, Eisenhauer B, Ruzicka D, Wottke M, Hausleiter J, Martinoff S, Morgenstern M, Lange R. Patency rates of endoscopically harvested radial arteries one year after coronary artery bypass grafting. J Thorac Cardiovasc Surg 2007;134:649-56.

25. Burris NS, Brown EN, Grant M, Kon ZN, Gibber M, Gu J, Schwartz K, Kallam S, Joshi A, Vitali R, Poston RS. Optical coherence tomography imaging as a quality assurance tool for evaluating endoscopic harvest of the radial artery. Ann Thorac Surg 2008;85:1271-7.

26. Lopes RD, Hafley GE, Allen KB, Ferguson TB, Peterson ED, Harrington RA, Mehta RH, Gibson CM, Mack MJ, Kouchoukos NT, Califf RM, Alexander JH. Endoscopic versus open vein-graft harvesting in coronary-artery bypass surgery. N Engl J Med 2009;361:235-44.

27. Agrifoglio M, Dainese L, Pasotti S, Galanti A, Cannata A, Roberto M, Parolari A, Biglioli P. Preoperative assessment of the radial artery for coronary artery bypass grafting: is the clinical Allen test adequate? Ann Thorac Surg 2005;79:570-2.

28. Medalion B, Tobar A, Yosibash Z, Stamler A, Sharoni E, Snir E, Porat E, Hochhauser E. Vasoreactivity and histology of the radial artery: comparison of open versus endoscopic approaches. Eur J Cardiothorac Surg 2008;34:845-9.

29. Rao C, Aziz O, Deeba S, Chow A, Jones C, Ni Z, Papastavrou L, Rahman $S$, Darzi A, Athanasiou T. Is minimally invasive harvesting of the great saphenous vein for coronary artery bypass surgery a cost-effective technique? J Thorac Cardiovasc Surg 2008;135:809-15. 